\title{
Optimasi Rute Distribusi Menggunakan Metode Tabu Search Perusahaan Daerah Air Minum (PDAM) Tirta Bangun Kulon Progo
}

\section{Optimization of Distribution Routes Using the Tabu Search Method of Tirta Bangun Progo Drinking Water Company}

\author{
Siti Dinar Rezki Ramadhani ${ }^{1 *}$, Hafizhta Aryunda Tanggono², Rif'an Yusuf ${ }^{3}$ \\ ${ }^{1}$ Program Studi Teknik Teknik Industri, Universitas Islam Indonesia \\ ${ }^{2,3}$ Program Studi Teknik Teknik Industri, Universitas Islam Negeri
}

\begin{abstract}
ARTICLE INFO
Article history:

DOI:

$\underline{10.30595 / p s p f s . v 11.134}$

Submitted:

June 26, 2021

Accepted:

July 13, 2021

Published:

Oct 31, 2021

ABSTRACT

Logistics management is known as distribution and transportation management, while others call it physical distribution management. Distribution activities are very important for companies to deliver a product to consumers across various regions. The Regional Drinking Water Company (PDAM) Tirta Binangun Kulon Progo is one of the companies that produce Bottled Drinking Water (AMDK) under the product name AirKu. The high demand for AMDK AirKu products in $240 \mathrm{ml}$ cup packaging was causing limited vehicles and the absence of a clear standard distribution route, which caused the distribution process to be carried out randomly. Therefore, to overcome the company's problems, it is possible to determine the Vehicle Routing Problem (VRP) route with the CVRP approach, where the route determination is based on fleet capacity. The method used was tabu search using the MATLAB application to minimize the bottled product delivery route traveled. The results obtained were the total distance traveled by $284.9 \mathrm{~km}$. The proposed route had a distance savings of $118.26 \mathrm{~km}$, which is better than the company route.
\end{abstract}

This work is licensed under a Creative Commons Attribution 4.0 International License.

Keywords:

Distribution, CVRP, Tabu

Search, PDAM

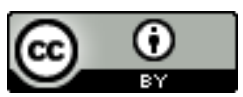

Corresponding Author:

Siti Dinar Rezki Ramadhani

Program Studi Teknik Teknik Industri, Universitas Islam Indonesia

J1. Kaliurang Km. 14,5 Krawitan, Kec. Ngemplak, Kabupaten Sleman, Daerah Istimewa Yogyakarta (55584)

Email: siti.dinar123@gmail.com

\section{PENDAHULUAN}

Manajemen logistik dikenal dengan sebutan manajemen distribusi dan transportasi, adapun yang menyebutnya dengan distribusi manajemen fisik. Fungsi umum distribusi dan transportasi ialah menghantarkan produk dari lokasi dimana produk tersebut diproduksi sampai dimana mereka akan digunakan. Kegiatan distribusi dan transportasi sangat penting karena penentuan rute pengiriman memiliki beberapa tujuan yang ingin dicapai seperti tujuan untuk meminimumkan biaya pengiriman, meminimumkan waktu atau meminimumkan jarak tempuh (Pujawan dan Mahendrawathi, 2010). Oleh karena itu untuk pemilihan metode penentuan rute secara tepat harus dilakukan oleh perusahaan dengan benar-benar optimal untuk meminimasi jarak dan biaya distribusi.

Permasalahaan penentuan rute dilakukan dengan pengembangan model Vehicle Routing Problem (VRP) untuk sejumlah kendaraan yang berbeda, dalam satu atau lebih depot sehingga bisa melayani konsumen yang tersebar secara geografis (Garside et al., 2018). Transportasi merupakan aspek terpenting dari logistik dan infrastruktur dasar bagi pertumbuhan ekonomi (Affi., 2018). Penyelesaian VRP yaitu untuk mencari rute perjalanan yang memiliki biaya paling rendah. VRP dapat menetukan skema rute terbaik untuk satu atau beberapa kendaraan dengan biaya terendah 
(Irie., 2019). VRP dapat dibagi menjadi dua metode yaitu metode konvensional dan metode heuristik. Metode heuristik dibagi menjadi dua yaitu heuristik klasik dan metode metaheuristik. Metaheuristik dapat didefinisikan sebagai metode lanjut berbasis heuristik untuk menyelesaikan persoalan optimasi secara efisien. Metode metaheuristik mampu menghasilkan solusi yang lebih teliti sehingga diahasilkan solusi yang lebih baik dalam waktu penyelesaian yang cepat (Lin et al., 2014).

Permasalahan dalam penentuan rute, salah satunya adalah Capacitated Vehicle Routing Problem (CVRP). CVRP adalah suatu permasalahan yang berkaitan dengan penentuan rute yang optimal dengan memperhatikan kendala setiap kendaraan yang memiliki kapasitas tertentu (Dreo et al., 2006). CVRP dapat diselesaikan dengan metode tabu search, metode tabu search sendiri salah satu algoritma metaheuristik untuk permasalahaan penentuan rute / VRP. Metode Tabu search merupakan penyelesaian dengan cara pencarian local yang tidak dapat menemukan solusi yang lebih baik kecuali optimal (Akbar et al.,2020). Maka, dapat disimpulkan bahwa metode tabu search dapat menyelsaikan CVRP.

Perusahaan Daerah Air Minum (PDAM) Tirta Binangun merupakan salah satu perusahaan yang memproduksi Air Minum Dalam Kemasan (AMDK) dengan nama produk Air Ku. Produk Air Ku pertama kali muncul pada tahun 2018 yang hanya tersedia dalam ukuran gelas/ cup $240 \mathrm{ml}$ dan dikemas dalam bentuk dus, dimana dus berisi 48 gelas/cup. Permasalahan yang ada pada perusahaan belum terdapat rute khusus dengan tingginya permintaan bisa mencapai lebih dari 400 dus per hari. Permasalahan lain adalah terbatasnya jumlah kendaraan di perusahaan. Kondisi ini menjadikan ketidak konsistenan rute pendistribusian di setiap pengiriman. Berdasarkan hal tersebut, penentuan rute yang baik menjadi hal yang penting bagi perusahaan agar produk dapat dikirim hingga sampai kepada konsumen secara tepat waktu, dan barang dalam kondisi baik. Maka dari itu untuk mengatasi permasalahan perusahaan dapat diselesaikan dengan pendekatan CVRP metode tabu search dimana penentuan rute berdasarkan kapasitas armada untuk meminimumkan total jarak tempuh.

\section{METODE PENELITIAN}

Pada bagian ini berisi tentang data obyek penelitian, metode pengumpulan data, metode pengolahan dan penyelesaian masalah. Terdapat 29 agen yang tersebar di daerah Kulon Progo yang permintaannya pada bulan September 2019. Berikut tabel 1. Sumber Data yang digunakan merupakan data yang digunakan dalam penelitian ini dan informasi sumber data:

Tabel 1. Sumber Data

\begin{tabular}{ll}
\hline \multicolumn{1}{c}{ Data } & Sumber \\
\hline Rute Awal Perusahaan Airku pada bulan September 2019 & Kepala Produksi \\
Permintaan Air Ku bulan September 2019 & \\
Alamat Agen & Kepala Marketing PDAM Tirta Binagun \\
Jenis dan Kapasitas Armada & \\
Titik Lokasi Agen & google maps \\
Matrix Jarak & google maps \\
\hline
\end{tabular}

Untuk pendistribusian produknya, PDAM Tirta Binangun memiliki 1 unit kendaraan dengan jenis Daihatsu Grand Max Box Panjang 2,3m x Lebar 1,65m xTinggi 1,35m dengan kapasitas 150 karton (box) AirKu gelas ukuran $240 \mathrm{ml}$.

Penyelesaian masalah dalam penelitian ini dilakukan dengan menggunakan metode Tabu search. Dalam proses pengolahan data menggunakan software MATLAB versi 2016. Data yang digunakan pada metode ini adalah sebagai berikut:

Solusi Awal menggunakan (Nearest neighbour)

a. Tentukan rute inisial (awal / Gudang AMDK AirKu)

b. Pilih node terdekat dengan tetangga terdekat (AMDK AirKu dan agen i)

c. Lakukan pemilihan rute terdekat dengan node sebelumnya hingga kapasitas tidak lebih atau sama dengan kapasitas armada ( $Q \leq$ kap. kendaraan).

d. Apabila kapasitas telah terpenuhi armada kembali ke depot dan membentuk rute baru. Kembali ke langkah (b).

e. Apabila sudah tidak ada rute, maka pencarian berhenti. Sehingga hasil akhir dari Nearest neighbour adalah clustering rute distribusi.

Tabu search

Konsep dasar dari Tabu Search adalah suatu algoritma yang menuntun setiap tahapannya agar dapat menghasilkan fungsi tujuan yang paling optimum tanpa terjebak ke dalam solusi awal yang ditemukan selama tahapan 
ini berlangsung. Tujuan algoritma ini mencegah terjadinya perulangan dan ditemukannya solusi yang sama pada suatu iterasi yang akan digunakan lagi pada iterasi selanjutnya (Oktarina et al., 2016).

Tabu search merupakan metode metaheuristik digunakan untuk memecahkan masalahan pada penelitian ini karena Tabu search sebagai metode yang memiliki solusi mendekati optimal pada kasus penentuan rute. Tabu search juga terdapat tabu list yang digunakan untuk menyimpan sekumpulan solusi.

Berdasarkan gambar di atas menurut Glover (1990) metode Tabu search terdiri atas :

1. Pembangkitan solusi awal sebagai current solution

2. Menentukan tabu restriction dan aspirasi kriteria (aspiration criteria) atau menentukan tujuan yang hendak dicapai

3. Menentukan stopping criteria. Stopping criteria yang umum digunakan pada tabu search yaitu:

- Setelah ditentukannya jumlah iterasi

- Setelah terjadi sejumlah iterasi tanpa adanya perkembangan pada fungsi tujuan (kriteria ini paling banyak digunakan)

- Ketika tujuan mencapai nilai yang telah ditentukan

4. Melakukan move yang akan menghasilkan solusi baru.

5. Update tabu list. Tabu list berisi atribut solusi-sousi yang telah dikunjungi sebelumnya.

6. Cycling, apabila solusi belum mencapai aspirasi kriteria maka dilanjutkan ke iterasi berikutnya dan cycle terjadi.

Namun, jika solusi telah mencapai aspirasi kriteria maka pencarian berhenti

\section{HASIL DAN PEMBAHASAN}

Perusahaan melakukan distribusi ke 29 agen yang tersebar di daerah Kulon Progo dengan jumlah permintaan sebanyak 974 dus pada bulan September. Untuk mempermudah penulisan maka dilakukan penotasian uang ditunjukan pada tabel 2. Informasi data, sebagai berikut :

Tabel 2. Informasi Data

\begin{tabular}{|c|c|c|c|c|c|c|c|}
\hline No & Notasi & Nama Agen & $\begin{array}{c}\text { Jumlah } \\
\text { permintaan } \\
\text { (Dus) }\end{array}$ & no & Notasi & Nama Agen & $\begin{array}{c}\text { Jumlah } \\
\text { permintaan } \\
\text { (Dus) } \\
\end{array}$ \\
\hline 1 & Gud & $\begin{array}{l}\text { Pabrik AMDK } \\
\text { "AirKu" }\end{array}$ & 0 & 16 & $\mathbf{O}$ & $\begin{array}{c}\text { Dinas Kesehatan } \\
\text { Kulon Progo }\end{array}$ & 43 \\
\hline 2 & $\mathbf{A}$ & $\begin{array}{l}\text { Perusahaan Umum } \\
\text { Daerah }\end{array}$ & 70 & 17 & $\mathbf{P}$ & Paud Sadewa & 20 \\
\hline 3 & B & Kantor Pos Wates & 70 & 18 & $\mathbf{Q}$ & $\begin{array}{c}\text { Bakpia Wingko } \\
\text { Rahmat }\end{array}$ & 60 \\
\hline 4 & $\mathbf{C}$ & TB Temon Baru & 70 & 19 & $\mathbf{R}$ & $\begin{array}{c}\text { Perum } \\
\text { Krembangan Asri }\end{array}$ & 20 \\
\hline 5 & D & RM Cengkir Gading & 70 & 20 & $\mathbf{S}$ & $\begin{array}{l}\text { Kantor PDAM } \\
\text { Tirta Binangun }\end{array}$ & 10 \\
\hline 6 & $\mathbf{E}$ & Toko Restu Ibu & 7 & 21 & $\mathbf{T}$ & $\begin{array}{l}\text { Polres Kulon } \\
\text { Progo }\end{array}$ & 20 \\
\hline 7 & $\mathbf{F}$ & Hyper Cell & 50 & 22 & $\mathbf{U}$ & $\begin{array}{c}\text { Bika Ambon Ya } \\
\text { Larizo Wates }\end{array}$ & 70 \\
\hline 8 & $\mathbf{G}$ & Toko Karya Jaya & 10 & 23 & $\mathbf{V}$ & Toko Abadi Pripih & 70 \\
\hline 9 & $\mathbf{H}$ & $\begin{array}{l}\text { Tomira (Indomaret) } \\
\text { Sentolo }\end{array}$ & 10 & 24 & $\mathbf{W}$ & Toko Vida & 20 \\
\hline 10 & $\mathbf{I}$ & Indomaret Wates 2 & 30 & 25 & $\mathbf{X}$ & Tomira Brosot & 35 \\
\hline 11 & $\mathbf{J}$ & $\begin{array}{l}\text { Tomira Wahid } \\
\text { Hasim }\end{array}$ & 40 & 26 & $\mathbf{Y}$ & $\begin{array}{c}\text { Kantor Kecamatan } \\
\text { Kokap }\end{array}$ & 7 \\
\hline 12 & $\mathbf{K}$ & Pujo Mart & 50 & 27 & $\mathbf{Z}$ & $\begin{array}{l}\text { Dinas Kebudayaan } \\
\text { Kulon Progo }\end{array}$ & 8 \\
\hline 13 & $\mathbf{L}$ & $\begin{array}{c}\text { BUMDes Banjarsari } \\
\text { SMP }\end{array}$ & 30 & 28 & $\mathbf{A A}$ & Tomira Dekso & 25 \\
\hline 14 & $\mathbf{M}$ & $\begin{array}{c}\text { Muhammadiyah } 2 \\
\text { Wates }\end{array}$ & 20 & 29 & AB & Toko Bu Sri & 15 \\
\hline
\end{tabular}




\begin{tabular}{llclllll}
\hline $\mathbf{1 5}$ & $\mathbf{N}$ & $\begin{array}{l}\text { SMK } \\
\text { Muhammadiyah 2 } \\
\text { Wates }\end{array}$ & 15 & $\mathbf{3 0}$ & AC & $\begin{array}{l}\text { Kantor Pajak } \\
\text { Kulon Progo }\end{array}$ & 9 \\
\hline
\end{tabular}

Perusahaan melakukan proses distribusi produk AMDK Air Ku ukuran gelas/ cup $240 \mathrm{ml}$ pada bulan September 2019 rute distribusi perusahaan yang ditunjukkan pada tabel 3. Rute Perusahaan dibawah ini:

Tabel 3. Rute Perusahaan

\begin{tabular}{cccc}
\hline Rute & Rute yang ditempuh & Total Jarak $\mathbf{( K m )}$ & Total Angkut (Dus) \\
\hline Rute 1 & Gud-A-B-Gud & 11,01 & 140 \\
Rute 2 & Gud-C-D-Gud & 30,65 & 140 \\
Rute 3 & Gud-E-F-G-H-I-J-Gud & 93,1 & 147 \\
Rute 4 & Gud-K-L-M-N-Gud & 76,2 & 115 \\
Rute 5 & Gud-O-P-Q-R-Gud & 38,4 & 143 \\
Rute 6 & Gud-S-T-U-Gud & 16,1 & 100 \\
Rute 7 & Gud-V-W-X-Y-Z-Gud & 85,5 & 140 \\
Rute 8 & Gud-AA-AB-AC-Gud & 52,2 & 49 \\
\hline & Total & $\mathbf{4 0 3 , 1 6}$ & $\mathbf{9 7 4}$ \\
\hline
\end{tabular}

Pada analisis penentuan rute pendistribusian produk AMDK AirKu wilayahKulon Progo ini, yang pertama dilakukan adalah mengidentifikasi jumlah permintaan dari masing-masing agen, lokasi dan jarak antar agen. Dimana Matriks jarak dan kapasitas kemudian diolahmenggunakan metode tabu search yaitu dimulai dari mencari rute solusi awal berdasarkan nearest neighbour untuk akumulasi kapasitas kendaraan (rute inisiasi) kemudian jarak solusi awal tersebut di iterasi maksimum sehingga ditemukan jarak yang optimum. Mencari solusi awal dari jarak yang terdekat berdasarkan metode nearest neighbour. Berikut tabel 5. solusi awal perhitungan menggunakan aplikasi matlab.

Tabel 5. Solusi Awal

\begin{tabular}{|c|c|c|c|}
\hline Rute & Notasi Agen & Total Jarak & Total Angkut (Dus) \\
\hline Rute 1 & Gud - G -W -D -Gud & 18.75 & 100 \\
\hline Rute 2 & Gud - Q - Z - B - Gud & 11.15 & 138 \\
\hline Rute 3 & Gud - U - I - Gud & 11 & 100 \\
\hline Rute 4 & Gud - AB - A - S - O - AC - Gud & 20.35 & 147 \\
\hline Rute 5 & Gud - T - R - P - H - E - AA - L - Gud & 61 & 132 \\
\hline Rute 6 & Gud - N - M - J - C - Gud & 32.6 & 145 \\
\hline Rute 7 & Gud - X - V - Y - Gud & 70.3 & 112 \\
\hline \multirow[t]{2}{*}{ Rute 8} & Gud - K - F Gud & 61.5 & 100 \\
\hline & Total & 286.65 & 974 \\
\hline
\end{tabular}

Untuk hasil perhitungan jarak distribusi produk AMDK Air Ku ukuran gelas/ cup 240 ml pada bulan September 2019 ditunjukkan pada tabel 6. Hasil perhitungan menggunakan tabusearch dibawah ini.

Tabel 6. Hasil Perhitungan Menggunakan Tabu Search

\begin{tabular}{llrr}
\hline Rute & Notasi Agen & Total Jarak & Total Angkut (Dus) \\
\hline Rute 1 & Gud - G - W -D -Gud & 18.75 & 100 \\
Rute 2 & Gud - Q - Z - B - Gud & 11.15 & 138 \\
Rute 3 & Gud - U - I - Gud & 11 & 100 \\
Rute 4 & Gud - AB -O - A -AC- S- Gud & 18.6 & 147 \\
Rute 5 & Gud - T - R - P - H - E - AA - L - Gud & 61 & 132 \\
Rute 6 & Gud - N - M - J - C - Gud & 32.6 & 145 \\
Rute 7 & Gud - Y - V - X - Gud & 70.3 & 112 \\
\hline
\end{tabular}




\begin{tabular}{rrrr}
\hline Rute 8 & Gud - K - F Gud & 61.5 & 100 \\
& Total & 284.9 & 974 \\
\hline
\end{tabular}

Berdasarkan output pengolahan data tabu search menggunakan aplikasi matlab diperoleh 8 rute dengan jarak $284,9 \mathrm{~km}$. Berikut perbandingan total jarak rute perusahaan dengan penyelesaian berdasarkan metode tabu search ditunjukkan pada tabel 7. Perbandingan Rute.

Tabel 7. Perbandingan Rute

\begin{tabular}{lcc}
\hline & Jumlah Rute & Total $(\mathbf{k m})$ \\
\hline Perusahaan Airku & 8 & 403.16 \\
Tabu search & 9 & 284.9 \\
& Penghematan Jarak & $\mathbf{1 1 8 . 2 6}$ \\
& Persentase penghematan jarak & $\mathbf{2 9 \%}$ \\
\hline
\end{tabular}

Tabel 7. Perbandingan rute menunjukan dengan metode tabu search dapat menghemat jarak sebesar $29 \%$ dengan 9 rute atau cluster.

\section{KESIMPULAN}

Berdasarkan hasil dan pembahasan didapatkan kesimpulanbahwa, rute perusahaan dengan total jarak distribusi sebesar 403,16 km kemudian berdasarkan pengolahan metode tabu search menjadi $284,9 \mathrm{~km}$ atau mengalami pengehematan total jarak tempuh sebesar $118,26 \mathrm{~km}$ atau $29 \%$.

\section{UCAPAN TERIMA KASIH}

Dengan selesainya penelitian ini, kami mengucapkan terima kasih kepada seluruh pihak yang tekait objek penelitian kepada Bapak Meirianto selaku Kepala Marketing dan Bapak Hartono selaku Kepala Produksi AMDK AirKu PDAM Tirta Binangun Kulon Progo atas segala infromasi selama proses penyusunan penelitian ini.

\section{DAFTAR PUSTAKA}

Affi, M., Derbel, H. \& Jarboui, B. (2018). Variable Neighborhood Search Algorithm For The Green Vehicle Routing Problem, International Journal of Industrial Engineering Computations, 9(2), pp. 195-204. Doi: 10.5267/j.ijiec.2017.6.004.

Akbar, M. D. and Aurachmana, R. (2020). Hybrid Genetic-Tabu Search Algorithm To Optimize The Route For Capacitated Vehicle Routing Problem With Time Window, International Journal of Industrial Optimization, 1(1), p. 15. doi: 10.12928/ijio.v1i1.1421.

Garside, A. K., \& Cahyani, D. N. (2018). Penyelesaian Vehicle Routing Problem with Simulate Pick Up and Delivery dengan Algoritma Tabu Search. Jurnal Ilmiah Teknik Industri, ISSN : 1412-6869.Vol.17 pp. 125-134.

Garside, A. K., \& Dewi R. 2017. Manajemen Logistik. Malang; Universitas Muhammadiyah Malang.

Glover, Fred. 1990. "Tabu Search: A Tutorial.” Interfaces 74-94.

Irie, H., Wongpaisarnsi, G., Terabe, M., Terave., Miki.A., \& Taguchi, S. (2019). Quantum Annealing of Vehicle Routing Problem with Time, State and Capacity. Quantum Technology and Optimization Problems (QTOP): Vol. 11413.doi: 10.1007/978-3-030-14082-3.

Lin, C.K.L., Choy, H. ,Chung., \& Lam, H.Y. (2014). Survey of Green Vehicle Routing Problem: Past and Future Trends. Expert Systems with Applications, Vol. 41, pp. 1118-1138.

Novinda., F.R. Martini, R and Aurahman., R.(2017). Penentuan Rute Armada Menggunakan Algoritma Tabu Search pada Homogenus Fleet Vehicle Routing Problem With Time Windows di PT.XYZ Wilayah Bandung untuk meminimasi Total Waktu Tempuh. E-Proceeding of Engineering. Vol.4,pp.2892.

Oktarina, S., Herni, F.M., and Fitria, L. (2016). Usulan Rute Distribusi Kopi Arabiaka Premium Menggunakan Tabu Search di PT.X. Jurnal Online Institut Teknologi Nasional. ISSN :2338-5081.Vol.4.pp.149-159.

Pujawan, I.N. \& Mahendrawathi, (2010). Supply Chain Management. Edisi kedua. Surabaya; Institut Teknologi Sepuluh November. 